\title{
O Negro Escravo e o Negro Liberto Numa Época de Transição. 0 Caso da Província de Buenos Aires
}

\section{Heloisa Jochims Reichel}

Esta comunicação pretende ilustrar, através do estudo do papel que o negro ocupou na vida econômica e na vida política da província de Buenos Aires dos inícios do século XIX, a participação da população negra no processo de transição para o surgimento de uma estrutura econômico-social capitalista na América Latina.

Inicialmente, focalizaremos o negro como força de trabalho no campo e na cidade ao final do período colonial, já que, até este momento, sua condição quase exclusiva de escravo assim delimitava a sua participação naquela sociedade.

Se observarmos as estatísticas sobre o número de negros presentes na província de Buenos Aires, verificamos que ele nunca foi muito elevado. Números apresentados por Concolorcorvo em seu testemunho de viagem, datado de 1773 , nos mostram que, para um total de 8.147 brancos (entre europeus e criollos), havia uma população de 4.163 negros escravos no território que correspondia à cidade de Santissima Trinidad e porto de Santa Maria de Buenos Aires. ${ }^{1} \mathrm{Da}$ mesma forma, esta situação se repetia, ou até mesmo se agravava, em 1810, quando os censos estatísticos da época registraram um contingente de 11.837 negros escravos, correspondente a menos de $50 \%$ do da população branca, que era de 28.116 pessoas. $^{2}$

Esta reduzida utilização da mão-de-obra escrava esteve diretamente relacionada com as atividades econômicas predominantes na região. Desde a sua fundação, Buenos Aires se dedicou à pecuária, na sua campanha, e ao comércio, na zona urbana - setores da economia que 
não se caracterizam por utilizar predominantemente o braço escravo. Além de absorver pouca mão-de-obra, a pecuária que se desenvolvia no final do período colonial tendia a empregar cada vez menos o escravo que, sendo caro e não estando acostumado ao manejo de cavalos e vacuns, se tornava um investimento de alto risco.

Nesse momento, torna-se necessário que nos refiramos sinteticamente às transformações que se operavam na criação de gado, ao final do século XVIII. A redução drástica dos rebanhos, em contradição com o crescente aumento da demanda de couros pelo mercado internacional, exigia uma crescente especialização dessa atividade. Por isso, as estâncias - unidades de produção básicas da pecuária - passavam por um "estado de transição". 3 apresentando-se às vezes sob os moldes de uma estância colonial ou, cada vez mais freqüente, sob a forma mais próxima da denominada moderna, que se dedica exclusivamente à criação e à reprodução do gado.

Uma das principais diferenças entre uma estância colonial e as de tipo mais moderno era estabelecida pelas atividades nelas desenvolvidas. Enquanto na colonial realizavam-se as atividades que envolviam desde a criação de gado até a comercialização do couro, nas outras ocorriam aquelas que se relacionavam quase que exclusivamente com o desenvolvimento dos rebanhos, com a venda do gado em pé para os saladeiros e para os abatedouros da cidade.

Em seu artigo "Una estancia en la campaña de Buenos Aires, Fontezuela - 1753-1809". Halperin Donghi nos fornece alguns elementos que ilustram a produção da estância colonial e sua relação com 0 mercado. Segundo o autor, ela concentrava suas atividades tanto na criação de gado vacum quanto cavalar, orientando-as para a produção de couros, sebo e banha, que tinham um duplo mercado: os produtos derivados de gado vacum eram comercializados em Buenos Aires, enquanto que os do cavalo eram vendidos na estância mesma. A criação de vacuns comportava o sacrifício e a elaboração dos produtos derivados na própria estância, sendo que para um total de 402 couros vendidos em 1771, por exemplo, apenas foram comercializados 25 animais vivos. Os ingressos financeiros da estância dependiam, principalmente, da comercialização do couro dus animais que servia inclusive de moeda. ${ }^{4}$

Os escravos realizavam as tarefas que podemos denominar de 'sedentárias' na estância colonial, ou seja, aquelas que não exigiam o uso 
do cavalo. Trabalhavam na produção de couros e do sebo principalmente, deixando aquelas relativas ao cuidado do gado nos rodeios, à sua marcação, doma ou preparação para o abate, aos peões da campanha. Assim, as alterações que ocorriam na estrutura da produção pecuária contribuíram também para a diminuição do número de escravos na província e, em especial, na campanha. À medida em que a estância colonial foi cedendo lugar à denominada por nós de 'moderna' e as tarefas que eram executadas pelos escravos, como produzir couro e sebo, passaram a ser realizadas nos saladeiros, junto das cidades, o trabalho nas estâncias ficou restrito àquelas atividades que utilizavam mão-de-obra livre e que, por exigirem grande habilidade no uso do cavalo e de certos instrumentos, eram desenvolvidas pelos nativos da região.

Em vista disso, mesmo antes da Independência, o maior contingente de negros morava na cidade onde realizava trabalhos domésticos, de artesanato e também de transporte, quase sempre na qualidade de escravo.

Ao considerarmos a década que segue o movimento de independência (1810-1820), verificamos que tanto a população negra quanto o emprego das relações de produção escravistas diminuíram mais ainda. Para um contingente de brancos que cresceu para 40.616, em 1822, o número de negros alcançou apenas 13.685 , sendo que, desses, somente 6.611 , ou seja, $48 \%$, eram escravos. ${ }^{5}$ Nesse momento, o pequeno crescimento da população negra em geral e a diminuição da de escravos ocorreram principalmente devido às decisões do governo independente que se instalara e que tiveram por objetivo abolir gradativamente a escravidão nas Províncias Unidas e atender às necessidades do exército nacional envolvido nas lutas contra os espanhóis e contra as províncias separatistas.

Nesse sentido, operaram os decretos de 9 de abril de 1812 e de 31 de janeiro de 1813, que proibiam o tráfico de escravos e adotavam o princípio do nascimento livre, respectivamente. Um outro decreto, de 4 de fevereiro de 1813, declarava livres todos os escravos introduzidos nas Províncias Unidas a partir daquela data e, em 6 de março do mesmo ano, a Assembléia Constituinte estendeu os limites dessa liberdade outorgada a outros filhos de escravos, estabelecendo que, até os 15 anos, eles deveriam trabalhar gratuitamente para seus amos e posteriormente mais 5 anos pelo pagamento de um peso por mês. ${ }^{6}$ Se considerarmos que o 
salário de um peão equivalia a 25 ou 30 pesos por mês nessa ocasião e que por um importante período de sua vida produtiva o trabalhador negro trabalhava quase gratuitamente, podemos verificar o quanto ainda ele continuava a ser explorado em Buenos Aires.

Também no sentido de possibilitar a abolição da escravatura, mas procurando ao mesmo tempo atender à necessidade que o exército tinha de conseguir homens que servissem como soldados nas constantes campanhas militares em que se envolvia, o governo assinou os decretos de 31 de maio e de 26 de junho de 1813, que criavam o primeiro batalhão de libertos, composto de escravos que obteriam a liberdade como recompensa pelo serviço militar prestado à nação. Com isso, já se delineia a principal ocupação dos libertos e a razão principal para a diminuição da população negra e de escravos na província, ou seja: o serviço nas tropas militares.

Esta constatação não invalida a força que as alterações da instância econômica tiveram na diminuição do uso das relações escravistas, mas serve, isto sim, para mostrar a inter-relação entre os fatores econômico, social e político. Como indicativo dessa interação, temos a considerar que os saladeiros, ao assumirem algumas das tarefas que antes eram realizadas nas estâncias, não se utilizaram de mão-de-obra escrava e sim assalariada, porque a nova legislação contribuiu para que ela se tornasse rara e o seu preço extremamente elevado.

A escravidão, entretanto, não desapareceu completamente nas zonas da campanha e das cidade. Rosas, como outros pecuaristas, continuou a se utilizar de mão-de-obra escrava, principalmente após os anos vinte, quando a produção pecuária começou a se expandir num ritmo mais intenso e a província, estando envolvida numa série de conflitos externos e internos, sofreu com a falta de mão-de-obra. Temos notícia de que, em 1822 e 1823, ele comprou 15 escravos para as estâncias dos Anchorena e, em 1828, efetuou novas compras, agora para as de sua propriedade. ${ }^{7}$ Nas suas Instrucciones a los mayordomos de estancias, preocupou-se com a manutenção e a reprodução de mão-de-obra escrava, determinando que fossem dadas, todas as segundas-feiras, rações aos escravos composta de "prata, tabaco, papel e sabão". 8

É necessario considerar que essas questões ocorreram num momento em que o governo assumia compromissos com a Inglaterra de abolir o tráfico de escravos, principal mecanismo de reposição da 
mão-de-obra escrava. Pelo Tratado de 2 de fevereiro de 1825, assinado com a Inglaterra, as Províncias Unidas eram obrigadas a cooperar na supressão total do tráfico de escravos em troca de benefícios financeiros e do reconhecimento de sua independência. Além disso, não podemos esquecer que o desaparecimento de muitos ex-escravos, quando da prestação do "serviço às armas" (as Províncias Unidas estavam em guerra contra o Brasil - 1826-28), não ensejou que a compra de novos escravos proporcionasse o crescimento da população negra na província, mas apenas que ela se mantivesse estável, como ocorreu ao longo da década de 30 .

Como era grande a falta de mão-de-obra durante esses anos, temos vários indícios que mostram que a escravidão ainda persistia como relação de produção na província, utilizada tanto no meio urbano quanto no rural. Neste sentido, verificamos que Rosas restabeleceu parcialmente o tráfico de escravos no início do seu governo, quando, através do decreto de 15 de outubro de 1831, permitiu a venda de escravos importados pelos estrangeiros como serventes "para fazer sentir aos desgraçados filhos da África os benefícios da civilização". 9 O comércio interno de escravos foi bastante intenso nesse período, sendo que os periódicos publicavam diariamente avisos que ofereciam escravos à venda e gratificações em troca de informações sobre escravos que fugiam. ${ }^{10}$ Relatórios dos chefes de polícia da campanha demonstram, por sua vez, a presença dos mesmos na zona rural, ao mencionarem a prisão de escravos presos por delitos como uso de cuchillo, assassinato, roubo, assim como multas impostas a pecuaristas que não liberavam seus escravos para servir no exército. ${ }^{11} \mathrm{~A}$ imprensa que fazia oposição a Rosas também testemunhou as relações escravistas na campanha ao afirmar que "ele deu um decreto há oito anos, permitindo introduzir negros escravos porque ele $e$ os Anchorenas os necessitam para as suas estâncias". ${ }^{12}$

A permanência dessas relações pode ser explicada também pela presença de pequenas propriedades que ainda produziam o couro e o sebo particularmente, como atestam alguns inventários daquela época. ${ }^{13}$

Preocupado com a falta de braços para o trabalho, o governo de Rosas procurou manter os vínculos existentes entre os ex-escravos e seus antigos amos, exigindo que estes exercessem suas atividades como homens livres, no mesmo local que o faziam quando eram escravos. Sendo assim e justificando que "tendo cessado os motivos que teve em 
vista ao expedir os decretos de 19 e 25 de fevereiro de 1831, ordenando que se entregasse para o serviço das armas os libertos de idade de 15 anos para cima, tanto na cidade quanto na campanha" decretou, em 10 de junho de 1836, o cessamento do efeito dos referidos decretos, mas determinou, ao mesmo tempo, que "todos os libertos [...] fossem devolvidos a seus respectivos patrões". ${ }^{14}$

Antes disso, em 25 de janeiro de 1831, já decretara que todo negro liberto através do serviço militar deveria receber um boleto firmado por seu amo e visado pelo juíz de paz de sua paróquia, onde deveria constar a sua qualificação e ser renovado a cada seis meses. ${ }^{15}$ Através desses mecanismos, a liberdade do ex-escravo passava a ser vigiada e devidamente conduzida para que ele continuasse a canalizar a sua força de trabalho para a produção e interesse dos seus antigos senhores.

As relações escravistas sofreram um recuo mais significativo a partir de 1839, quando Rosas, necessitando do auxílio inglês para enfrentar o bloqueio francês ao porto de Buenos Aires, assinou com a Inglaterra um acordo onde se comprometia a abolir de vez o tráfico de escravos. Com isso, a escravidão praticamente desapareceu da província, já que os negros que ali viviam eram libertados ou por servirem no exército ou por nascerem no país. O mesmo se pode dizer em relação à população negra que habitava a campanha, já que os poucos negros que restaram preferiram morar na cidade.

Apesar da escravidão aparecer formal e integralmente abolida na Argentina, apenas na Constituição de 1853, já em 1835, Woodbine Parish, Cônsul Geral e Encarregado de Negócios da Grã-Bretanha em Buenos Aires, assim se referia ao declínio das relações escravistas na região: "Asi se fue gradualmente extinguiendo la esclavatura del Rio de la Plata, sin dano ni queja por parte de sus amos, contribuyendo mucho a la mejora del carácter en general de los mismos esclavos, que acostumbrados seriamente a hábitos de disciplina y de trabajo antes de su emancipación, constituyen hoy quizá la más útil e industriosa de las clases bajas de la sociedad. Por todas partes donde hay trabajo vense acudir con sus alegres y renegridos rostros, en un clima en que pueden trabajar más que los demás. Los changadores, los carreteros y carreros, y casi todas las lavanderas de Buenos Aires, son negros libres o mulatas." 16

$\mathrm{O}$ que analisamos até agora sobre a atuação da mão-de-obra negra na província de Buenos Aires, nos permite verificar que, próprio de um 
momento de transição, as relações escravistas tenderam a desaparecer rapidamente à medida em que foram adotadas leis abolicionistas e se inibiu o tráfico de escravos. Enquanto este existiu, elas ainda se mantiveram apesar de perderem espaço gradativamente diante ao avanço das relações de produção livres. Ao mesmo tempo, como mão-de-obra livre, o negro continuou a realizar as mesmas tarefas que anteriormente executava na qualidade de escravo, muitas vezes nos mesmos locais e servindo aos seus antigos amos, o que, sem dúvida, limitou a liberdade conquistada. Além disso, as transformações que ocorriam na produção pecuária incrementou ainda mais a concentração da mão-de-obra negra na zona urbana.

Cabe agora analisarmos aquele que, para nós, foi o mais importante dos papéis executados pela população negra na cidade de Buenos Aires, após a Independência. Ele não foi de ordem econômica, mas fundamentalmente de base de sustentação e execução do projeto político da proto-burguesia latifundiária e pecuarista-exportadora que assumiu o controle do governo da província após Cepeda (1820) e a federalização das Províncias Unidas.

É no papel de executora do projeto expansionista da fronteira que temos que destacar a atuação dos negros após a Independência. Em troca da liberdade, eles se engajaram nas campanhas militares que buscavam consolidar a Independência. Mas, foi após o controle do governo pelos federais, que tinham a clara intenção de expandir a base pecuarista exportadora da economia buenairense, que os negros encontraram condições concretas e permanentes para em troca do serviço militar, obterem a liberdade.

Após a derrota dos unitários em Cepeda e a conseqüente federalização da província, Buenos Aires teve que procurar compensar a perda do controle comercial dos produtos exportados pelas demais Províncias Unidas, com o incremento da sua própria produção pecuária. Nesse momento, os negros começaram a ser utilizados como soldados que, em busca de novas terras, participaram no processo de construção de uma nova ordem social naquela região. Ao expandirem a fronteira ao sul do rio Salado (1810) até Tandil (1823) e depois, com a Conquista do Deserto comandada por Rosas (1833), eles contribuíram para que a sociedade buenairense apresentasse uma classe dominante composta pelo setor pecuarista-exportador que encontrava as bases da sua domi- 
nação numa pecuária forte, na existência de terras abundantes, na presença crescente do latifúndio e da propriedade privada dos bens de produção.

Os negros atuaram não só como executores do projeto federal, mas, também, como sustentadores do mesmo no seu confronto com o unitário. Sabe-se das profundas divisões políticas que dividiram os buenairenses até a derrota de Rosas em Caseros. Nesse confronto e ambiente de guerra civil, a população de cor desempenhou um papel fundamental de apoio à causa federal.

Esta adesão se deu, em parte, porquê, a partir da subida de Rosas ao poder em 1929, houve uma mobilização militar permanente, seja na conquista de novos territórios, seja na defesa das fronteiras contra os índios, seja na luta contra os unitários. Vários foram os negros que alcançaram a sua liberdade por servirem ao exército federal e, em conseqüência, foi grande o apoio e a adesão da população negra à causa federal. Alguns excertos da poesia La negrita (1830), retirada do cancioneiro popular da época, atestam o que afirmamos: "Yo me llamo Juana Pena / Y tengo por vanidad / Que sepan todos que soy / Negrito muy federal ... Yo por desgracia no tengo / Hijos, padre ni marido / a quien poderlos decir / que sigan este partido / Pero tendo a mis paisanos / Nos Negritos Defensores [...]." "17

Outro fator, que explica este forte apoio dos negros aos federais, encontramos no envolvimento personalista e "populista" que o discurso e a forma de atuar de Rosas junto às camadas populares produzia. As palavras de Rosas, escritas a sua esposa D. Encarnación, em 1833, quando se afastou da cidade para comandar a Campanha do Deserto, atestam o seu desejo de manipular os pobres e, em especial, os negros, transformando-os em sua base de apoio político e de enfrentamento junto aos seus adversários. Escreveu, ele: 'YYa has visto lo que vale la amistad de los pobres y por elle cuanto importa sosternela y no perder medios para atraer y cautivar voluntades. No cortes pues sus correspondencias. Escribeles con frecuencia: mandáles cualquier regalo, sin que te duela gastar en esto. Digo lo mismo respecto de las Madres y mujeres de los partos y morenos que son fieles. No repares, repito, en visitar a las que lo merezcany llevarlas a tus distracciones rurales, como tambiém en socorrerlas con 10 que puedas en sus desgracias". ${ }^{18}$

Rosas tinha muitos negros empregados e muitos outros a sell serviço político. Não os elevava socialmente, porém não exercia uma 
discriminação racial contra eles. Permitia-lhes a formação de sociedades, como a Sociedad Conga e a Nación Banguela, a comemoração de suas festas, como o Carnaval e bailes, e a prática de suas crenças, como o candomblé.

Em troca, os negros deram a Rosas seu cego apoio. Auxiliaram-lhe a compor as tropas militares que expandiram a fronteira da zona da campanha e, na cidade, integraram a unidade de milícia, a "negrada federal", que, com suas camisas vermelhas, defenderam a lei e a ordem dos federais.

Por tudo isso, podemos concluir afirmando a participação da papulação negra no processo de construção da formação social capitalista na província de Buenos Aires. Ela ocorreu, do ponto de vista econômico, porque o negro continuou a desempenhar suas funções sociais e relações de produção livres, mas principalmente, porque atuou concreta e entusiasticamente na defesa e na implementação do projeto da classe latifundiária-pecuarista-exportadora.

Tal foi o grau de sua participação neste processo que, podemos dizer, que ela pagou o preço da sua extinção quase completa da sociedade buenairense ao entregar sua vida na luta pela conquista das novas terras que iriam beneficiar somente os terratenientes.

\section{Notas}

1. CONCOLORCORVO. El lazarillo del ciegos caminantes. Buenos Aires, Solar, 1942. p.43.

2. LINCH, J. Juan Manuel de Rosas 1829-1852 2.ed., Buenos Aires, Emece, 1984. p.119.

3. In: MAC CANN, W. Viaje a caballo por las provincias argentinas. 3.ed., Buenos Aires, Solar/Hachette, 1969. p.118.

4. HALPERIN DONGHI, T. Una estancia en la campana de Buenos Aires, Fontezuela 1753-1809. In: FLORESCANO, E. (org). Haciendas, latifundios y plantaciones en America Latina. Mexico. Siglo XXI, 1975. p.447-63.

5. LINCH. op.cit.

6. Os decretos aparecem publicados em Decretos, Bandos, Leyes y Constituciones promulgados en la Provincia de Buenos Aires. 1810-1822. Buenos Aires, Imprenta Nacional, s.d.

7. LINCH. Op. cit, p.120.

8. ROSAS, J.M. Instrucciones a los mayordomos de las estancias. Buenos Aires, Americana, 1950. p.56.

9. BUENOS AIRES, Museo Mitre. Leyes y decretos de la Provincia de Buenos Aires. 1810-1876.

10. BUENOS AIRES AGN. Coleción Celesia. Jornal da Tarde, 1837.

11. BUENOS AIRES, AGN. DGN. Policia. Partes de Campana.

12. EL GRITO ARGENTINO. Buenos Aires, no2, p.2.

13. BUENOS AIRES. Op. cit. nota $\mathrm{n}^{211}$. 
14. BUENOS AIRES. AGN. DN. Secretaria de Rosas. Solicitudes. Decretos.

15. BUENOS AIRES. AGN. DGN. Policia. Partes de Campana, 1830.

16. ROMERO, L.A. Buenos Aires criolla 1820-1850. Buenos Aires, Centro Editor de America Latina, 1983. p.59-60.

17. Cancionero del tiempo de Rosas. Buenos Aires, Emecé, s.d. p.23-4.

18. LINCH. Op. cit. p.111. 